\title{
A lógica interna de um projeto: Heidegger e sua hermenêutica fenomenológica da facticidade
}

\section{Resenha de La transformación hermenéutica de la fenomenología: una interpretación de la obra temprana de Heidegger, de Ramón Rodríguez (San Martín: Unsam Edita, 2019)}

\author{
Luís Gabriel Provinciatto \\ lgprovinciatto@hotmail.com \\ (Universidade Federal de Juiz de Fora, Minas Gerais, Brasil)
}

DOI: http://dx.doi.org/10.11606/issn.2318-9800.v25i4p271-277

A primeira edição (1997) de La transformación hermenéutica de la fenomenología surgiu quando ainda não estavam publicados todos os textos precedentes a Ser e tempo (1927), obra magna de Martin Heidegger (1889-1976), trazendo uma contribuição inédita acerca do período inicial da docência do filósofo, conforme indica o próprio autor no prólogo à nova edição (2019). A obra agora reeditada, contudo, não traz nenhum acréscimo e/ou modificação em relação à primeira edição, donde a possibilidade de o(a) leitor(a), a princípio, imaginar haver a ausência de uma adequada fundamentação para falar, por exemplo, sobre a indicação formal (formale Anzeige), apresentada conceitualmente por Heidegger com maior precisão em Introdução à fenomenologia da religião (1920/1921), reunida no volume Fenomenologia da vida religiosa, ainda inédito quando da elaboração da primeira edição. Ledo engano. A leitura empreendida por Rodríguez é precisa, atenta e eficaz, o que torna sua obra primorosa para se entender a lógica interna da origem de uma hermenêutica fenomenológica da facticidade como proposta filosófica. Por isso, a delimitação teórica aí assumida não se justifica pela primeira passagem de Heidegger por Friburgo (1919-1923), mas pelas necessidades lógicas da vida fática, bem como por suas exigências metódicas. Com isso, dá-se maior precisão ao sentido de "transformação": não se trata de uma metamorfose que modifica a fenomenologia surgida nas Investigações lógicas (1900/1901) em algo completamente diferente, mas 
de um movimento fiel à exigência da máxima fenomenológica; ela também auxilia a entender a leitura fenomenológica que Heidegger faz da própria fenomenologia. Para cumprir seu propósito, Rodríguez assume duas hipóteses de interpretação, indicadas no prólogo à primeira edição e desenvolvidas ao longo dos sete capítulos da obra: a primeira afirma que, em Heidegger, há uma indissociabilidade entre o método e o tema da investigação, impossibilitando que se leia a fenomenologia desvinculada da hermenêutica da facticidade; já a segunda diz que a fenomenologia husserliana é a referência desse projeto filosófico, dando-lhe "o estilo e $o$ modo de compreensão filosófica capaz de levar a cabo com êxito o intento de autointerpretação da facticidade" (Rodríguez, 2019, p. 24).

As preleções A ideia da filosofia e o problema da visão de mundo (1919) guiam o primeiro capítulo, que aborda a busca de uma ciência originária por Heidegger, apresentando dois pontos fundamentais para entendê-la e, com isso, justificar sua função para o desenvolvimento de uma hermenêutica fenomenológica da facticidade: primeiro, a ideia de uma ciência originária já aparece em Husserl, que a desenvolve e caracteriza, sobretudo, no artigo A filosofia como ciência de rigor (1910/1911); segundo, há uma clara proximidade de Heidegger com a filosofia da vida, não propriamente com seus autores, mas com o tema da vida como fenômeno originário, acolhendo-o como indicação de uma tarefa e não enquanto conceito. Isso se mostra nas supracitadas preleções através da discussão com o transcendentalismo neokantiano e, mais especificamente, com aquilo que aí se denomina "vivência" (Erlebnis). Heidegger parte de um exemplo: o da vivência da pergunta "há algo?". Conforme indica Rodríguez, o que aí importa não é a pergunta em si, mas o que se pretende com ela. Trata-se de fazer ver que para que ela aconteça são necessários aspectos prévios, donde a relevância de outro exemplo, o da cátedra, que não é vista enquanto madeira, caixa e cor, senão imediatamente enquanto tal, isto é, em sua significação imediata: "o vivido é primordialmente as coisas mesmas e estas são, antes de tudo, sentidos, significados que imediatamente compreendo, com os quais estou constantemente lidando" (Rodríguez, 2019, p. 36). A descrição da vivência da cátedra como vivência do mundo circundante (Umwelterlebnis) oferece os aspectos prévios para que seja possível a vivência da pergunta. Fica evidente, portanto, que a vivência da pergunta expõe uma vivência já objetivada e, ao mesmo tempo, originária, a saber, a do mundo circundante enquanto significação, donde a posição assumida por Heidegger ser a de uma "tenaz defesa da vida originária contra as interpretações teorizantes dela" (idem, p. 38). Com isso, a filosofia como ciência originária deve partir do pré-objetivo, isto é, daquilo que é anterior a qualquer circunscrição teórica que defina o conteúdo da vivência como "objeto" e quem o vivencia como "sujeito". Tais preleções, mais do que expor uma problemática hermenêutica, indicam os motivos propriamente fenomenológicos que a conduzem. 
Nesse sentido, o segundo capítulo, dividido em dois blocos, apresenta a interpretação da ideia de fenomenologia por Heidegger. No primeiro bloco, fazse uma exposição sucinta dos pontos significativos das Investigações lógicas, dos quais se destacam o conceito de intencionalidade, a diferença demonstrada por Husserl entre ato intencional (vivência) e objeto e o significado do que é uma análise fenomenológica. No segundo, expõe-se que, para Heidegger, a fenomenologia deve descrever a vivência em seu caráter imediato, sem recorrer à divisão entre ato intencional e objeto - o princípio teórico da fenomenologia husserliana. Portanto, a fenomenologia deve realizar uma descrição direta, na qual "a exposição do sentido da vida originária, levada a cabo por Heidegger através da descrição concreta de uma vivência perceptiva da vida cotidiana [a vivência da cátedra], se atém ao que imediatamente se vive na vivência" (Rodríguez, 2019, p. 55). Não é necessário prescindir da relação noesis-noema e sim repensá-la desde um princípio que não seja teórico, o que conduz precisamente à problematização tanto do caráter ontológico da intencionalidade quanto da compreensão originária da vida. Assim, o segundo capítulo não é uma mera exposição das diferenças entre Husserl e Heidegger acerca do conceito de intencionalidade, mas um momento fundamental na economia da obra, pois situa muito bem a perspectiva heideggeriana em relação ao horizonte dentro do qual ela se movimenta.

O terceiro capítulo se detém justamente nesta perspectiva. Nele se reiteram dois aspectos fundamentais à fenomenologia: a intuição e a crítica. Trata-se de assumir uma posição que seja livre de um juízo prévio (crítica), mas que, ao mesmo tempo, não “crie” propriamente aquilo que investiga, senão que o perceba e o faça ver tal como é (intuição). Além disso, o capítulo também traz que, para Husserl, a fenomenologia é sempre um exercício reflexivo que converte a vivência em objeto. De acordo com Heidegger, porém, ao assim proceder, cria-se uma "ilusão fenomenológica" de que já se chegou às coisas mesmas e, com isso, assume-se a teoria não enquanto possibilidade de compreensão, mas como algo natural, dando à fenomenologia um princípio teorético, não originário, portanto, e que desvivifica a vivência. Tal princípio é rejeitado por Heidegger, que, por sua vez, conforme destaca Rodríguez, descreve a intuição como já sendo hermenêutica, fazendo dela um dos aspectos metódicos fundamentais para a realização de seu projeto. Assim, a primeira ideia de hermenêutica diz respeito a uma repetição da vivência, não em termos teórico-reflexivos, mas nos de "retomar em sua integridade tudo o que aparece no viver imediato e, muito especialmente, o modo não-teorético desse aparecer" (Rodríguez, 2019, p. 84), sendo, por isso, o dar-se a conhecer a si mesma da vida fática. Compreende-se, então, porque, em Heidegger, a vida originária não é apreendida enquanto processo (Vorgang), senão enquanto apropriação (Ereignis), bem como porque essa repetição, por não ser reflexiva, "recolhe o momento fenomenológico 
insuprível da doação da 'coisa mesma', do aparecer originário do sentido, e como repetição evidente, garante a formulação inteligível e a imprescindível comprovação do visto" (idem, p. 98).

Tudo isso conduz à Revisão hermenêutica da fenomenologia, título do quarto e principal capítulo da obra, para o qual as preleções de 1923, Ontologia. Hermenêutica da facticidade, e o escrito de 1922, Interpretações fenomenológicas sobre Aristóteles: indicação da situação hermenêutica, mais conhecido como Informe Natorp, são fundamentais, pois apresentam e conceituam o que é a situação hermenêutica, bem como tratam de sua apropriação e, sobretudo, de sua condição de possibilidade e de sua orientação prévia. Ratifica-se, então, que a ideia de hermenêutica, para Heidegger, não é a doutrina das condições de interpretação de textos históricos, mas, antes, diz respeito ao modo como "a vida fática se dá a conhecer a si mesma, partindo do e se mantendo no conhecimento imediato - não reflexivo - que tem de si mesma e no qual constantemente se desenvolve” (Rodríguez, 2019, p. 99). Entendese, assim, porque a vida como fenômeno originário é assumida por Heidegger não como conceito, mas como indicação de uma tarefa: a fenomenologia deve vê-la a partir do modo como ela mesma se vê e, consequentemente, de toda autocompreensão imediata que tem de si. Nesses termos, a situação hermenêutica não pode estar cindida daquilo que compreende, donde a conclusão: a situação hermenêutica é a própria vida fática, de modo que esclarecê-la é trazer à tona suas categorias fundamentais, evidenciando as condições de possibilidade da autocompreensão, e mais, da apropriação dessa autocompreensão. Com isso, sinaliza-se para a tarefa ontológica própria à hermenêutica fenomenológica da facticidade, o que será melhor trabalhado nos capítulos subsequentes.

A apropriação da situação hermenêutica está balizada em três momentos: antes da compreensão, há algo previamente dado; o sentido disso que está dado não é evidente em si mesmo - “não é inteligível por sua pura doação” (Rodríguez, 2019, p. 107) -, pois, caso assim fosse, doação e compreensão seriam o mesmo ato; tal apropriação é autoapropriação.

De acordo com essa estrutura, a situação hermenêutica precede o ato filosófico primeiro momento -, mas não como algo que the é anterior, como um acontecimento ao qual se possa se dirigir objetivamente, senão como algo que ele mesmo é - terceiro momento -, que lhe é "natural" e que, em certo sentido, não constitui seu tema ou objeto (noema), mas integra seu próprio ser ato (noesis). Justamente por isso, ele não é imediatamente inteligível, não é transparente para si mesmo - segundo momento - e requer uma explicação (idem, ibidem).

Isso, contudo, não torna a filosofia idêntica à vida fática, donde a dificuldade de posicionar com precisão a própria hermenêutica da facticidade: ela já é um ato filosófico? Se sim, viver é filosofar. Se não, a filosofia necessita de uma conversão do e 
A lógica interna de um projeto: Heidegger e sua hermenêutica fenomenológica...

no próprio olhar para acontecer. Por isso, “'situação hermenêutica' e 'vida fática' não são duas 'coisas' diferentes, pois ambas se referem ao mesmo ente, o ser que somos nós mesmos (Dasein); porém, não significam o mesmo, não se apresentam da mesma maneira" (Rodríguez, 2019, p. 109). A problemática em torno à apropriação não pode ser algo à parte à fenomenologia, senão dela constituinte, ou seja, uma fase de sua própria tarefa hermenêutica. A apropriação da situação hermenêutica deve dizer respeito à condição hodierna de compreensão, partindo sempre da cotidianidade da vida fática e não de condições excepcionais. Isso delimita a situação hermenêutica em um horizonte de compreensão previamente estabelecido. Tem-se, assim, que a condição de possibilidade da orientação prévia que conduz a compreensão imediata da vida fática não é autenticada pelo horizonte histórico no qual o Dasein já sempre se encontra, senão pelo fato de que há uma relação intencional entre vida e mundo. Portanto, só há orientação prévia porque há intencionalidade, que, por sua vez, sempre está direcionada a algo já o compreendendo: “o ser-no-mundo entendido como existência, como aquele ser que tem que ser, constitui a orientação prévia que guia a hermenêutica da vida fática” (idem, p. 127). Assim, ser é o horizonte ao qual o ver fenomenológico está previamente orientado e o ser-no-mundo a orientação prévia de tal olhar.

O quinto capítulo aborda justamente a primazia hermenêutica da pergunta pelo ser e, para isso, retoma a discussão iniciada no terceiro. Agora, no entanto, Rodríguez mostra por que, de acordo com Heidegger, Husserl, ao não chegar a problematizar o ser da intencionalidade e ao se manter na esteira do cartesianismo, assume a consciência como algo simplesmente dado (Vorhandenheit). Além do mais, através da redução fenomenológica, Husserl distingue entre ser e originariedade, que, para Heidegger, estão radicalmente unidos. Para Husserl, portanto, a atitude natural seria assumir o ser no sentido da objetividade, ou seja, de “(ser) verdadeiro para um conhecer teórico" (Rodríguez, 2019, p. 143). Donde o ponto decisivo da crítica heideggeriana: a atitude natural não pode ter caráter reflexivo, tampouco teórico, visto que a reflexão e a teoria são posições (atitudes) assumidas pelo pensar. "A verdadeira atitude natural, aquela na qual vivemos antes de toda reflexão e que precede sempre a qualquer consideração filosófica ou teórica, não é justamente uma atitude, porque não é algo que se tome ou adote, mas algo em que sempre já se está" (idem, ibidem), o que conduzirá à conclusão de que a facticidade é um fundamento infundado (Abgrund), conforme será demonstrado no sétimo capítulo.

As categorias ontológicas da vida fática, então, não podem advir senão dela mesma, pois, caso contrário, cair-se-ia em um princípio teórico, extrínseco à facticidade. Como garantir legitimidade a tais categorias? Essa é a pergunta com a qual Rodríguez se ocupa no sexto capítulo, cujo propósito não é analisar cada uma das categorias ontológicas da vida fática, mas mostrar como elas são possíveis e 
justificáveis. Para tanto, trata-se de mostrar como os conceitos fenomenológicos são evidentes - não evidência de essência, como em Husserl, mas evidência do sentido como algo que acontece sempre de maneira situada - e, ao mesmo tempo, não determinam definitivamente aquilo que descrevem. Isso só é possível se tais conceitos foram indicações formais. Mesmo não tendo à disposição as preleções nas quais a indicação formal é devidamente apresentada e conceituada, como dito acima, Rodríguez segue atentamente as pistas deixadas por Heidegger, sobretudo, nas preleções Interpretações fenomenológicas sobre Aristóteles: introdução à investigação fenomenológica (1921/1922) para desvendar a forma e a origem dos conceitos fenomenológicos. Destaca-se o principal recurso por ele utilizado: a analogia entre a indicação formal (Heidegger) e a categoria formal (Husserl), estabelecendo similaridades e diferenças entre ambas, tornando viável estabelecer a relação da indicação formal com a formalização e a generalização tal qual também apresentadas por Husserl, o que se comprovará com a posterior publicação das preleções Introdução à fenomenologia da religião.

Destaca-se ainda a nova e pertinente aproximação com Husserl, sobretudo, no que diz respeito à retomada da tese kantiana sobre o ser como não sendo um predicado real: isso importa porque tanto em Husserl quanto em Heidegger, por um lado, "a nova objetividade que aflora na intuição categorial não afeta em nada o objeto mostrado na percepção sensível” (Rodríguez, 2019, p. 164) e, por outro, "está excluída da ideia de uma intuição 'pura', direta, do categorial” (idem, p. 165). Ou seja, só há categoria porque há fenômeno. Diferentemente de Husserl, porém, Heidegger concebe o categorial não como um ato reflexivo posterior, senão na própria situação objetiva. Justifica-se, assim, porque as categorias existenciais não podem surgir senão na própria condição fática da vida e, com isso, porque a comprovação das mesmas não pode estar em outro lugar senão que "no saber de si presente nos comportamentos nos quais a categoria está sendo exercida" (idem, p. 171).

O capítulo que encerra a obra de Ramón Rodríguez continua abordando a legitimidade da hermenêutica da facticidade, mostrando agora por que é válida a proposta de uma "correta orientação" para ela. 0 primeiro ponto aqui elucidado é o fato de a vida fática sempre se assumir impropriamente, ou seja, "não trazendo consigo uma compreensão de seu ser tal como ele é” (Rodríguez, 2019, p. 174). Por isso, a autocompreensão da vida fática advinda da vivência do mundo circundante, embora seja a primeira a ser realizada, não deve ser a definitiva, pois, na lida cotidiana, o Dasein tende a se ocupar com as coisas do mundo circundante, absorvendo-se nelas, deixando-se levar por elas. Trata-se, pois, de uma compreensão que iguala ser e ente. Por não tematizar o ser e não o trazer tal como é, ela é pré-ontológica. Além disso, "a auto interpretação imediata da facticidade vive sob a primazia ontológica da Vorhandenheit" (idem, p. 179). Não se trata, contudo, de estabelecer, a partir disso, 
critérios de valor, mas de perceber que essa “desfiguração" é uma condição da própria facticidade, que, por assim dizer, encobre o originário. A destruição fenomenológica, nesse cenário, surge como não sendo só um aspecto metodológico utilizado para a leitura dos conceitos herdados da tradição, mas um para se alcançar a vida fática em propriedade, desencobrindo seus aspectos fundamentais: “destruição para um sentido apontado, pré-compreendido no fato mesmo de destruir e que, através da destruição, chega ao estado de fenômeno" (idem, p. 189). Tem-se, assim, a possibilidade de passagem da condição de impropriedade à de propriedade. Tal passagem, no entanto, não será alcançada mediante um exercício reflexivo, pelas razões já apontadas no terceiro capítulo, tampouco poderá prescindir do eu-histórico que compreende sua facticidade já de maneira imprópria, pois, caso dele prescindisse, criar-se-ia uma sombra, ou melhor, uma idealização da vida fática em propriedade. Portanto, o contra movimento à tendência à impropriedade também surge faticamente: em Prolegômenos para uma história do conceito de tempo (1925), Heidegger afirma que isso é possível a partir de uma experiência fundamental (Grunderfahrung), da qual a angústia seria o principal exemplo, mostrando, assim, a importância da afetividade (Befindlichkeit) para o caminho fenomenológico heideggeriano. 0 destaque dado à angústia se dá justamente porque ela independe de qualquer determinação mundana, deixando o Dasein lançado consigo mesmo em sua própria situação, a saber, de que ele tem que ser. A abertura causada pela angústia torna possível a correta relação com as coisas, com os outros e consigo mesmo, mostrando a facticidade como origem, logo, como aquilo que deve ser investigado fenomenologicamente.

Tem-se, por fim, uma contribuição ímpar para os estudos acerca do pensamento de Heidegger. A presente obra deve, sem dúvida, figurar entre as principais pesquisas referentes ao período anterior à publicação de Ser e tempo. Lê-la é uma oportunidade única para qualificar o entendimento de qualquer leitor(a) a respeito do projeto da hermenêutica fenomenológica da facticidade. Também não há dúvida de que a literatura em português certamente seria enriquecida com a publicação de uma tradução do presente texto, justificada pela sua primorosa qualidade e pela indiscutivel qualidade que ela agregaria às pesquisas que há tempos já são feitas neste idioma.

Recebido em: 20.06.2020

Aceito em: $16 \cdot 10.2020$

Esta obra está licenciada com uma Licença Creative Commons Atribuição-NãoComercial-Compartilhalgual 4.0 Internacional. https://creativecommons.org/licenses/by-nc-sa/4.0/

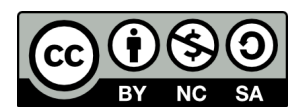

